\title{
O SIGNIFICADO DA EXPRESSÃO EFICÁCIA HORIZONTAL DOS DIREITOS FUNDAMENTAIS
}

\section{THE MEANING OF THE EXPRESSION HORIZONTAL EFFECT OF FUNDAMENTAL RIGHTS}

\section{EL SIGNIFICADO DE LA EXPRESIÓN EFICACIA HORIZONTAL DE LOS DERECHOS FUNDAMENTALES}

Marcelo Schenk Duque ${ }^{1}$

Licença CC BY:

Artigo distribuído sob os termos Creative

Commons, permite uso e distribuição irrestrita em qualquer meio desde que o autor credite a fonte original.
Resumo: A pesquisa tem por objetivo desvendar o significado da expressão "eficácia horizontal dos direitos fundamentais". São apresentadas as diferentes concepções sobre o tema, em particular a partir da doutrina alemã, responsável pelo maior desenvolvimento científico atribuído à matéria dos direitos fundamentais nas relações privadas. A partir da análise da controvérsia, percebese que a questão da eficácia horizontal dos direitos fundamentais é muito mais complexa que a tradicional eficácia vertical, que vincula os órgãos estatais. Para demonstrar essa realidade, o estudo emprega o método dedutivo, com técnica de pesquisa focada na revisão bibliográfica e jurisprudencial.

Palavras-chave: Eficácia horizontal; direitos fundamentais; Constituição; Direito Constitucional

Abstract: This study aims to clarify the meaning of the expression "horizontal effect of fundamental rights". Different concepts of the expression are presented, in particular those from the German doctrine, which is responsible for the greater scientific development attributed to the effectiveness of fundamental rights in private relations. The analysis of the controversy shows that the issue of the horizontal effect of fundamental rights is much more complex than the traditional vertical effect, which binds state agencies. In order to demonstrate this reality, this study applies the deductive method, with research techniques focused on bibliographic and case law review.

1 Marcelo Schenk Duque. Doutor em Direito do Estado pela UFRGS/ed. Ruprecht-Karls-Universität Heidelberg, Alemanha. Pesquisador convidado junto ao Europa Institut da Universidade de Saarland, Alemanha. Professor do programa de pós-graduação stricto sensu da Faculdade de Direito da UFRGS (Porto Alegre/RS, Brasil); Coordenador Acadêmico do Curso de Especialização em Direito do Estado da UFRGS. Professor da Escola da Magistratura Federal do Estado do Rio Grande do Sul - ESMAFE/RS, onde exerce a coordenação da matéria de direito constitucional; Professor de diversos cursos de Pós-graduação lato sensu da UFRGS, PUC/RS, AJURIS FEMARGS, FESDEPRS, FMP, dentre outros. Professor da Faculdade Dom Bosco de Porto Alegre. Professor da Escola Superior de Advocacia da OAB/RS. Membro da Associação Luso-Alemã de Juristas: DLJV - DeutschLusitanische Juristenvereinigung. Endereço eletrônico: marceloschenk@gmail.com 


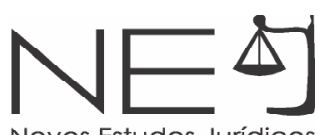

Keywords: Horizontal effect; fundamental rights; Constitution; Constitutional Law

Resumen: La investigación tiene por objetivo descifrar el significado de la expresión "eficacia horizontal de los derechos fundamentales". Son presentadas las diferentes concepciones sobre el tema, en particular a partir de la doctrina alemana, responsable por el mayor desarrollo científico asignado a la materia de los derechos fundamentales en las relaciones privadas. A partir del análisis de la controversia, se percibe que la cuestión de la eficacia horizontal de los derechos fundamentales es mucho más complejo que la tradicional eficacia vertical, que vincula los órganos estatales. Para demostrar esa realidad, el estudio emplea el método deductivo, con técnica de investigación focada en la revisión bibliográfica y jurisprudencial.

Palabras clave: Eficacia horizontal; derechos fundamentales; Constitución; Derecho Constitucional.

\section{INTRODUÇÃO}

O presente estudo tem por objetivo desvendar o significado da expressão "eficácia horizontal dos direitos fundamentais", termo que se origina da expressão em língua alemã Drittwirkung der Grundrechte. A relevância do tema reside no fato de que a dogmática dos direitos fundamentais assume uma importância fundamental nos dias atuais, considerando as ameaças que provêm não apenas dos Poderes Públicos, como igualmente dos setores privados da sociedade. Assim, entender como se fundamenta a eficácia dos direitos fundamentais nas relações privadas é um imperativo do constitucionalismo contemporâneo.

A hipótese de pesquisa é de que a construção que fundamenta a eficácia dos direitos fundamentais nas relações privadas é significativamente mais complexa do que a eficácia desses direitos perante os órgãos estatais. As diversas teorias que estudam o tema comprovam essa realidade. Considerando a grande controvérsia a que o tema se sujeita, o presente estudo adota como marco referencial teórico estudos de autores nacionais e estrangeiros. Particularmente, confere-se destaque às fontes alemãs de pesquisa, considerando que, de fato, a Alemanha é o pais que melhor logrou êxito em estudar o fenômeno da vinculação dos particulares aos direitos fundamentais. Assim, utilizando-se o método de pesquisa dedutivo e a técnica de revisão bibliográfica e jurisprudencial, a pesquisa visa a contribuir para o debate em torno da eficácia dos direitos fundamentais no ordenamento jurídico pátrio.

\section{FIXAÇÃO DAS PREMISSAS PARA O ESTUDO DA EFICÁCIA HORIZONTAL DOS DIREITOS FUNDAMENTAIS}

O estudo da eficácia horizontal dos direitos fundamentais requer uma compreensão quanto ao seu objeto. Isso passa por uma definição básica acerca da abrangência do fenômeno jurídico, bem como da terminologia que costuma ser empregada para descrevê-lo, o que se deixa compreender pela análise da origem do debate doutrinário e jurisprudencial. 


\subsection{SIGNIFICADO DA EXPRESSÃO "EFICÁCIA HORIZONTAL DOS DIREITOS FUNDAMENTAIS"}

Os direitos fundamentais são resultado de um longo processo de maturação histórica, que envolve luta, conquistas e por vezes até retrocessos. A questão da eficácia horizontal dos direitos fundamentais representa um importante recorte na sua compreensão. Acima de tudo, um recorte positivo, pois amplia o significado e alcance dos direitos fundamentais, justamente na direção de seu significado maior: a promoção do ser humano. O sentido da expressão "eficácia horizontal" aponta para a eficácia dos direitos fundamentais no curso de relações privadas, ou seja, para aquelas relações onde o Estado não atua diretamente. ${ }^{2}$ Seu sentido maior está na constatação de que as relações privadas não podem ser consideradas um campo imune à incidência dos direitos fundamentais. Em outras palavras, aponta para a necessidade de compreensão em torno de uma vinculação dos particulares aos direitos fundamentais. Remete a uma questão principal, cuja complexidade não pode ser desconsiderada: como uma norma de direito fundamental pode ser aplicada no curso de relações jurídicas travadas entre particulares? ${ }^{3}$

O ponto central da análise é o reconhecimento de que determinados direitos fundamentais, em particular aqueles que possuem significado no tráfego jurídico privado, além de vincularem os poderes públicos, ${ }^{4}$ devem considerar-se direito vinculante nas relações jurídicas levadas a efeito entre sujeitos privados, no sentido de que as pessoas privadas, naturais ou jurídicas, devem observar os direitos fundamentais quando se colocam em contato jurídico com outros sujeitos de Direito Privado. ${ }^{5}$ Trata-se de perspectiva que abre a incidência dos direitos fundamentais para vários âmbitos do ordenamento jurídico, em nítida contraposição ao pensamento clássico, presente na fase inicial do constitucionalismo liberal ${ }_{1}^{6}$ de que os direitos fundamentais possuíam significado apenas como direitos de defesa, oponíveis contra o Estado, na clássica acepção de Georg Jellinek. ${ }^{7}$

O tema da eficácia horizontal é marcado por grandes controvérsias, seja no que diz respeito à forma de penetração dos direitos fundamentais no ordenamento jurídico privado, seja no que tange à intensidade desta vinculação. ${ }^{8}$ Em particular, discute-se com afinco o alcance e as consequências desse efeito horizontal. ${ }^{9}$ Ciente de que o princípio da igualdade não proíbe de modo absoluto

2 Para aprofundamento, vide DUQUE, Marcelo Schenk. Eficácia Horizontal dos Direitos Fundamentais e Jurisdição Constitucional. 2 ed. revista e ampliada. São Paulo: Editora dos Editores, 2019, p. 10ss.

3 BYDLINSKI, Franz. Kriterien und Sinn der Unterscheidung von Privatrecht und öffentlichem Recht. Archiv für die civilistische Praxis (AcP), Band 194. Tübingen: Mohr, 1994, p. 332 (nota 26). HESSE, Konrad. Grundzüge des Verfassungsrechts der Bundesrepublik Deutschland. Neudruck der 20. Auflage. Heidelberg: Müller, 1999, Rdnr. 345ss.

5 STERN, Klaus. Das Staatsrecht der Bundesrepublik Deutschland: Allgemeine Lehren der Grundrechte. München: Beck, 1988, Band III/1, p. 1.512s.

6 MENEZES, Aderson de. Teoria geral do Estado. 8. ed. rev. e atual. Rio de Janeiro: Forense, 2009, p. 237ss.

7 JELLINEK, Georg. System der Subjektiven Öffentlichen Rechte. 2. Auf. Tübingen: Mohr, 1919, p. 69ss.

8 DUQUE, Marcelo Schenk. Eficácia Horizontal dos Direitos Fundamentais..., p. 48ss.

9 DIMOULIS, Dimitri; MARTINS, Leonardo. Teoria Geral dos Direitos Fundamentais. 3 ed. São Paulo: Revista dos Tribunais, p. 104. 


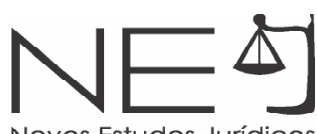

diferenciações de tratamento, mas sim as chamadas diferenciações arbitrárias ${ }^{10}$ e que ao Estado não é dado suprimir as liberdades reconhecidas pelos direitos fundamentais com a simples aplicação do princípio da igualdade, ${ }^{11}$ cumpre investigar o tema a partir de diversas perspectivas. À medida que todos os particulares costumam ser titulares dos mesmos direitos fundamentais, o problema da eficácia horizontal torna-se, inegavelmente, uma questão ligada ao conflito, que enseja constante ponderação de bens, ${ }^{12}$ em um cenário onde a busca da segurança jurídica e da fundamentação racional das decisões não pode ser menosprezada. ${ }^{13}$

Certo é que o pensamento jurídico é uma obra em constante evolução, o que torna complexa a questão não apenas sobre o futuro da Constituição, ${ }^{14}$ enquanto ordem fundamental jurídica da coletividade, ${ }^{15}$ como também sobre o papel e eficácia dos próprios direitos fundamentais. Independentemente dessa realidade, há uma espécie de consenso na doutrina no sentido de que os direitos fundamentais não mais podem ser desconsiderados no curso das relações privadas, como se possuíssem sentido apenas nas relações travadas com entes públicos. É exatamente para esse lado que se volta a questão da assim denominada eficácia horizontal dos direitos fundamentais.

\subsection{ORIGEM DO DEBATE EM TORNO DA EFICÁCIA HORIZONTAL DOS} DIREITOS FUNDAMENTAIS

A temática da eficácia horizontal dos direitos fundamentais foi inserida no bojo de uma intensa discussão jurídica travada na segunda metade do Século $\mathrm{XX}$, mais precisamente nos anos cinquenta e sessenta, expressando um fenômeno que foi originalmente concebido e estudado na Alemanha sob a denominação de Drittwirkung der Grundrechte, que, em tradução livre, significa "eficácia dos direitos fundamentais perante terceiros" ${ }^{\prime 16}$. Essa é a razão pela qual a doutrina alemã é muito rica nesse debate, sendo fonte permanente de consulta no âmbito da discussão da eficácia horizontal, ciente de que temática adquiriu uma dimensão internacional, por não se tratar, de forma alguma, de um fenômeno puramente alemão. ${ }^{17}$

A doutrina alemã informa que foi no âmbito das relações privadas de trabalho que o tema adquiriu o seu impulso inicial e que isso não ocorreu por acaso. Indiscutivelmente, trata-se de um

10 FERREIRA FILHO, Manoel Gonçalves. Curso de Direito Constitucional. 36. ed. São Paulo: Saraiva, 2010, p. 309.

11 MENDES, Gilmar Ferreira. Direitos fundamentais e controle de constitucionalidade: estudos de direito constitucional. 4. ed., rev. ampl. São Paulo: Saraiva, 2012, p. 123.

12 BARROSO, Luís Roberto. Curso de Direito Constitucional Contemporâneo: os conceitos fundamentais e a construção do novo modelo. 2 ed. São Paulo: Saraiva, p. 336s.

13 ÁVILA, Humberto. Segurança Jurídica. Entre permanência, mudança e realização no Direito Tributário. São Paulo: Malheiros, 2011, p. 127ss.

14 GRIMM, Dieter. Entstehungs- und Wirkungsbedingungen des modernen Konstitutionalismus. In: GRIMM, Dieter. Die Zukunft der Verfassung. Frankfurt am Main: Suhrkamp, 1991, p. 31.

15 HESSE, Konrad. Grundzüge des Verfassungsrechts der Bundesrepublik Deutschland..., Rdnr. 17.

16 DUQUE, Marcelo Schenk. Eficácia Horizontal dos Direitos Fundamentais..., p. 10ss.

17 CANARIS, Claus-Wilhelm. Grundrechte und Privatrecht. Eine Zwischenbilanz. Berlin - New York: Walter de Gruyter, 1999, p. 10. 
campo jurídico onde os direitos fundamentais costumam adquirir um significado preponderante, mesmo sem a presença direta do Estado em um dos polos da relação. Isso ocorre porque as relações de trabalho costumam revelar uma nítida desigualdade de poder, manifestada na real possibilidade de uma parte, considerada mais forte (empregador), restringir direitos fundamentais da parte considerada mais fraca (empregado).

Várias situações nesse sentido foram colocadas perante as instâncias trabalhistas alemãs desde o início da década de cinquenta. Típicos foram os casos que investigaram a possibilidade de o empregador influenciar a opinião do empregado sobre determinados assuntos, de conflitos de consciência interferirem em relações de trabalho, de obrigação imposta a trabalhadoras de não contrair matrimônio ou de ter filhos, dentre outros. ${ }^{18}$

Nesse quadro, as primeiras grandes decisões de que se tem notícia, que reconheceram a eficácia dos direitos fundamentais nas relações privadas, foram tomadas pelo órgão de cúpula da jurisdição trabalhista alemã, o Tribunal Federal do Trabalho).

Note-se que nos dias atuais, em particular no cenário brasileiro, a matéria permanece atual. Há muitos conflitos envolvendo violações de direitos fundamentais no curso de relações trabalhistas, que passam por questões que dizem respeito a possíveis violações no âmbito da privacidade dos trabalhadores em conflito com políticas de segurança das empresas (por exemplo, monitoramento de e-mails, filmagens, revistas íntimas, etc.), passando por questões ligadas à própria saúde e segurança dos trabalhadores (não fornecimento de EPI's, obrigação de permanência prolongada em locais insalubres ou perigosos), obrigação de trabalhadoras de permanecerem ao longo da jornada de trabalho calçadas com sapatos de salto alto, maquiadas em excesso, etc, passando até mesmo por questões de assédio de todos os tipos ou até mesmo de trabalho escravo, além de outras situações degradantes.

Em síntese, a origem do tema da eficácia horizontal se deu no seio de relações trabalhistas de natureza eminentemente privada. Formou-se a convicção de que uma linha significativa de direitos fundamentais não deve garantir a liberdade somente perante o poder estatal, haja vista que na condição de preceitos ordenadores para a vida social, também possuem significado para as relações privadas. Por trás desta constatação está a ideia básica de que negócios de natureza jurídico-privada não podem entrar em contradição com aquilo que se entende como ordem pública de um Estado. ${ }^{19}$

É fácil perceber que a temática da eficácia horizontal não se esgota nas relações de trabalho. Elas serviram apenas como ponto de partida para a discussão. Com efeito, foi por meio de uma controvérsia em torno dos limites da liberdade de expressão, debatidos pelo Tribunal Constitucional Federal alemão no multicitado caso Lüth, que a temática da eficácia horizontal dos direitos fundamentais

18 NIPPERDEY, Hans Carl. Die Würde des Menschen. In: NEUMANN, Franz L; NIPPERDEY, Hans Carl; SCHEUNER, Ulrich (Hrsg.). Die Grundrechte. Handbuch der Theorie und Praxis der Grundrechte. Berlin: Duncler \& Humblot, 1954, Band II, p. 1ss.

19 Assim foi construída a jurisprudência do Tribunal Federal do Trabalho alemão. Vide, neste sentido, BAGE 1, 185 (NJW 1955, p. 607). 
ganhou, pela primeira vez, ampla discussão em um Tribunal Constitucional. ${ }^{20}$ Atualmente, a temática alastrou-se para os mais variados campos jurídicos, em particular para aqueles onde se verifica uma indiscutível desigualdade de forças no assim denominado tráfego jurídico-privado, com destaque para as relações de consumo, onde se afirma a construção do contrato como ponto de encontro de direitos fundamentais. ${ }^{21}$

\subsection{QUESTÕES TERMINOLÓGICAS}

Na literatura especializada, vários termos são sugeridos para expressar o fenômeno da eficácia dos direitos fundamentais nas relações privadas, como, por exemplo, eficácia perante terceiros, vinculação dos particulares aos direitos fundamentais, validade dos direitos fundamentais no âmbito privado ou simplesmente eficácia dos direitos fundamentais no Direito Privado, dentre outros. O próprio termo alemão, Drittwirkung, também é correntemente utilizado, haja vista que se tornou uma expressão clássica. De fato, no âmbito do Direito comparado, a expressão Drittwirkung ainda parece ser mais recorrente. ${ }^{22}$ Já a doutrina nacional parece inclinar-se, majoritariamente, à expressão "eficácia horizontal", ${ }^{23}$ referindo-se a assim denominada ameaça horizontal aos direitos fundamentais, ${ }^{24}$ muito

20 Trata-se de um caso julgado pelo Tribunal Constitucional Federal alemão (BVerfG) em 15 de janeiro de 1958, envolvendo um conflito relacionado aos limites da liberdade de manifestação do pensamento entre particulares. Em síntese, Erich Lüth, por ocasião da abertura de um festival cinematográfico realizado no ano de 1950, na cidade de Hamburgo, sustentou um boicote público contra o filme Unsterbliche Gelibte (amada imortal), dirigido pelo cineasta Veit Harlan, cujas atividades, durante o Terceiro Reich, foram marcadas pela produção de um filme de cunho notoriamente antissemita (Jud Süß). Referido boicote deu-se em face da remessa, por parte de Lüth, de uma carta aberta à imprensa, na qual exortava as empresas alemãs atuantes no ramo cinematográfico a não comercializarem o filme em questão; da mesma forma, incitava o público, em geral, a não o assistir. A produtora responsável pelo filme objeto do boicote, temendo as repercussões negativas daí advindas, ingressou com uma medida judicial destinada à suspensão do ato, obtendo êxito nas instâncias ordinárias do Poder Judiciário alemão. A matéria foi submetida ao Tribunal Constitucional Federal, sob o fundamento de violação ao direito fundamental de liberdade de expressão que, segundo Lüth, protege também a possibilidade de influir sobre os outros mediante o uso da palavra. O Tribunal acolheu o recurso por meio de uma das mais famosas decisões de sua história, que justamente recebeu o nome do recorrente (Lüth). Em suma, a decisão consagrou a tese de que o juiz civil pode violar direitos fundamentais por meio de sua sentença, quando ele desconhece a influência dos direitos fundamentais (a sua eficácia) sobre o direito civil, cabendo à jurisdição constitucional apreciar a "eficácia irradiante" dos direitos fundamentais sobre o direito civil e trazer à vigência, neste âmbito jurídico, o conteúdo valorativo dos preceitos jurídico-constitucionais. Para detalhes do caso, veja DUQUE, Marcelo Schenk. Eficácia Horizontal dos Direitos Fundamentais..., p. 26ss.

21 MARQUES, Claudia Lima. Contratos no código de defesa do consumidor: o novo regime das relações contratuais. 8. ed. São Paulo: Revista dos Tribunais, 2016, p. 256ss.

22 Comparar em ALEXY, Robert. Theorie der Grundrechte. Baden-Baden: Suhrkamp, 1994, p. 475ss; STERN, Klaus. Das Staatsrecht der Bundesrepublik Deutschland, p. 1.512; MÜNCH, Ingo von. Die Drittwirkung von Grundrechten in Deutschland. In: SALVADOR CODERCH, Pablo. (Coord.). Zur Drittwirkung der Grundrechte. Frankfurt: Peter Lang, 1998, p. 12; LÜCKE, Jörg. Die Drittwirkung der Grundrechte an Hand des Art. 19 Abs. 3 GG. Zur horizontalen Geltung der Grundrechte in neuer Sicht. Juristen Zeitung, 1999, n. ${ }^{\circ} 08$, p. 377ss; CHEREDNYCHENKO, Olha O. Fundamental Rights. Contract Law and the Protection of the Weaker Party. A Comparative Analysis of the Constitutionalisation of Contract Law, with Emphasis on Risky Financial Transactions. München: Sellier European Law Publishers, 2007, p. 122ss; 141ss; VEGA GARCÍA, Pedro de. Dificuldades y Problemas Para la Construcción de un Constitucionalismo de la Igualdad (en caso de la eficacia horizontal de los derechos fundamentales). In: PÉREZ LUÑO, Antonio Henrique (coord). Derechos Humanos y Constitucionalismo ante el Tercer Milenio. Madrid: Marcial Pons, 1996, p. 265ss; CANOTILHO, José Joaquim Gomes. Direito Constitucional e Teoria da Constituição. 6.ed. Coimbra: Almedina, 2002, p. 1273; MIRANDA, Jorge. Manual de Direito Constitucional. 3.ed. Coimbra: Coimbra Editora, 2000, Tomo IV, p. 321.

23 Vide, por ex, SARMENTO, Daniel. Direitos Fundamentais e Relações Privadas. Rio de Janeiro: Lúmen Juris, 2004, p. 223ss.

24 SILVA, Virgílio Afonso da. A Constitucionalização do Direito. Os direitos fundamentais nas relações entre particulares. São Paulo: Malheiros, 2005, p. 52s. 
embora não exista uma uniformidade terminológica. Sem embargo, como é comum no estudo da eficácia dos direitos fundamentais nas relações privadas, nem mesmo a difundida expressão eficácia horizontal fica isenta de polêmicas. A ideia de uma vinculação dos particulares aos direitos fundamentais exprime, ao fim e ao cabo, a possibilidade de os direitos fundamentais serem considerados direito vinculante na ordem jurídico-privada. ${ }^{25}$ Essa eficácia horizontal, que envolve a relação cidadãocidadão, resulta do alargamento da tradicional concepção em torno de uma eficácia vertical dos direitos fundamentais, ou seja, as relações cidadão-Estado. ${ }^{26}$ Ao que tudo indica, o emprego do termo "horizontal" visa a diferenciar as relações privadas da clássica relação de subordinação do cidadão perante o Estado (relação vertical), que durante décadas representou um elemento distintivo do Direito Público perante o Direito Privado. ${ }^{27}$

As críticas dirigidas pela doutrina ao termo eficácia horizontal resultam do fato de que as relações privadas nas quais o reconhecimento da vigência dos direitos fundamentais se faz mais necessário, são justamente aquelas marcadas por assimetrias ou desigualdades fáticas, como nitidamente ocorre, por exemplo, nas relações de consumo. ${ }^{28}$ São, portanto, relações não necessariamente horizontais, no sentido comum do termo, já que marcadas por flagrante desigualdade de poder. ${ }^{29}$ É por isso que há quem afirme que quando a sociedade deixa inteiramente livres os fortes e os fracos, a liberdade acaba se tornando mais efetiva para os primeiros. ${ }^{30}$

Isso se verifica em face da circunstância de um dos polos desse tipo de relação deter isoladamente, e em inegável superioridade, uma parcela de poder social, situação que pode levar, de maneira geral, à violação de direitos e, em particular, à restrição do espaço de liberdade da parte que detém a menor parcela de poder na relação. ${ }^{31}$ Essa crítica é útil para alertar que a terminologia eficácia horizontal não pode levar à falsa conclusão de que os particulares mantêm, necessariamente, relações simétricas, circunstância que ingressaria em contradição com a própria razão de ser do

25 MENDES, Gilmar Ferreira. Direitos fundamentais e controle de constitucionalidade..., p. 116ss.

26 STERN, Klaus. Das Staatsrecht der Bundesrepublik Deutschland..., p. 1.512. Contudo, que há quem visualize a questão do ponto de vista da validez. Nesse sentido, vide a crítica de MARTíNEZ, Gregorio Peces-Barba. Curso de derechos fundamentales - Teoria general. Madrid: Universidad Carlos III, 1995, p. 618 e 624, ponderando que a extensão dos direitos fundamentais nas relações de direito privado não é um problema de eficácia, mas sim de validez. Para o autor, devem-se distinguir dois temas: o primeiro é o âmbito da validez, no qual se verifica a existência das normas de direitos fundamentais nas relações entre particulares; o segundo é o âmbito da eficácia desses direitos, cuja garantia dá-se mediante o acesso aos tribunais constitucionais.

27 MÜNCH, Ingo von. Die Drittwirkung von Grundrechten in Deutschland..., p. 12s.

28 MARQUES, Claudia Lima. Sugestões para uma lei sobre o tratamento do superendividamento de pessoas físicas em contratos de crédito ao consumo: proposições com base em pesquisa empírica de 100 casos no Rio Grande do Sul. RDC. São Paulo: Revista dos Tribunais, n. 55, jul.-set. 2005, p. 11ss.

29 MARTINY, Anke. Die Verbraucher als zersplitterte Gegenmacht im Markt. In: PIEPENBROCK, Hartwig; SCHROEDER, Conrad (Hrsg.). Verbraucherpolitik Kontrovers. Köln: Deutscher Instituts-Verlag, 1987, p. 71ss.

30 SARMENTO, Daniel. Direitos Fundamentais e Relações Privadas..., p. 303s, sugerindo que quanto maior for a desigualdade, maior deverá ser a proteção pelos direitos fundamentais e menor a tutela conferida pela autonomia privada.

31 UBILLOS, Juan María Bilbao. La eficácia de los derechos fundamentales frente a particulares. Madrid: Centro de Estúdios Políticos y Constitucionales, 1997, p. 244, destacando que a assimetria entre os polos de uma relação privada assemelha-se às relações de natureza vertical, típicas das situações em que se situam um particular e um órgão estatal. Entre nós, vide DIMOULIS, Dimitri; MARTINS, Leonardo. Teoria Geral dos Direitos Fundamentais..., p. 104s. 


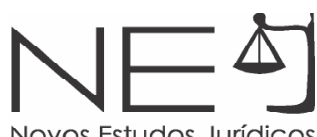

reconhecimento da eficácia dos direitos fundamentais nas relações privadas. Ainda, do ponto de vista da terminologia, observa-se que diferentes países optaram por diferentes terminologias para a questão. Nos Estados Unidos, por exemplo, o tema foi tratado sob a perspectiva da doutrina da State Action, ${ }^{32}$ cujo foco parece ser a necessidade de preservação da autonomia privada, $^{33}$ de viés tipicamente liberal, ${ }^{34}$ dificultando a fundamentação em torno de uma eficácia horizontal propriamente dita, evoluindo para uma ideia de função púbica, segundo a qual quando particulares agirem no exercício de atividades de natureza tipicamente estatal, estariam sujeitos às limitações constitucionais, ${ }^{35}$ por meio de uma fundamentação em torno de uma conexão ou implicação estatal, no curso de atividades privadas. ${ }^{36}$

A ideia é verificar em que medida uma conduta privada pode ser imputada, de uma forma ou de outra, ao Estado, de forma a atrair a proteção da Constituição. ${ }^{37}$ Dito de outro modo, trata-se de saber se o ato de uma pessoa privada direta ou indiretamente agressor de princípios constitucionais pode ser imputado ao Estado. ${ }^{38}$ Independentemente disso, há inúmeros precedentes da Suprema Corte que indicam a necessidade de preservação de direitos fundamentais mesmo no curso de relações privadas, ${ }^{39}$ adquirindo o tema interesse por parte da doutrina daquele país.

\subsection{DELIMITAÇÃO DO CAMPO DE APLICAÇÃO DA EFICÁCIA HORIZONTAL}

Nem todos os direitos fundamentais integram a perspectiva da eficácia horizontal. ${ }^{40}$ Essa constatação é importante, para que haja uma correta limitação do tema. Deve-se excluir da discussão todo e qualquer direito fundamental que não possua aplicação nas relações privadas. Essa observação decorre da circunstância de que nem todas as normas de direitos fundamentais vinculam os particulares, por serem, em princípio, destinadas tão somente aos órgãos estatais, na acepção de típicos direitos de defesa, oponíveis pela pessoa contra o Estado.

Isso não significa, todavia, que todos os direitos de defesa, ou de primeira geração, possuam significado apenas perante o Poder Público. Significa, apenas, que determinados direitos não possuem sentido no curso de relações eminentemente privadas. Um exemplo típico são as normas

32 TUSHNET, Mark. The issue of state action/horizontal effect in comparative constitutional law. Oxford University Press and New York University School of Law 2003, I Com, Volume 1, Number 1, 2003, p. 79ss.

33 TRIBE, Laurence. American Constitucional Law. 2 ed. Mineola: Foundation Press, 1988, p. 1.691.

34 SARLET, Ingo Wolfgang. Direitos Fundamentais e Direito Privado: algumas considerações em torno da vinculação dos particulares aos direitos fundamentais. In: SARLET, Ingo Wolfgang (org.). A Constituição Concretizada: construindo pontes com o público e o privado. Porto Alegre: Livraria do Advogado, 2000, p. 138.

35 SARMENTO, Daniel. Direitos Fundamentais e Relações Privadas..., p. 229.

36 UBILLOS, Juan María Bilbao. ¿En qué medida vinculan a los particulares los derechos fundamentales? In: SARLET, Ingo Wolfgang (Org.). Constituição, direitos fundamentais e direito privado. Porto Alegre: Livraria do Advogado, 2003. p. 318.

37 STEINMETZ, Wilson Antônio. A Vinculação dos Particulares a Direitos Fundamentais. São Paulo: Malheiros, 2004, p. 179.

38 CANOTILHO, José Joaquim Gomes. Civilização do Direito Constitucional ou Constitucionalização do Direito Civil? A eficácia dos direitos fundamentais na ordem jurídico-civil no contexto do direito pós-moderno. In: GRAU, Eros Roberto; GUERRA FILHO, Willis Santiago (orgs.). Direito Constitucional. Estudos em homenagem a Paulo Bonavides. São Paulo: Malheiros, 2001, p. 109.

39 SARMENTO, Daniel. Direitos Fundamentais e Relações Privadas..., p. 231ss; SILVA, Virgílio Afonso da. A Constitucionalização do Direito..., 2005, p. 19s.

40 SARLET, Ingo Wolfgang. Direitos Fundamentais e Direito Privado..., p. 116. 
fundamentais que conferem direito à nacionalidade, direitos de asilo, não extradição, garantias do processo penal, etc. ${ }^{41}$ Faça-se, no entanto, a anotação de que mesmo alguns dos direitos fundamentais que estão direcionados a priori ao Poder Público possuem eficácia nas relações entre particulares, considerando que vinculam os Poderes Legislativo e Judiciário, quando da elaboração e aplicação das regras de direito privado, sob a égide da Constituição. ${ }^{42}$ Nessa perspectiva, nota-se que uma das questões centrais da eficácia horizontal é saber quando o Poder Judiciário pode ou tem que, necessariamente, recorrer à Constituição, ao lado do direito infraconstitucional, para a solução da controvérsia privada que lhe é apresentada. ${ }^{43}$

O enquadramento dos direitos fundamentais no curso de relações privadas deriva, normalmente, da ligação desses direitos com a proteção da personalidade humana. Isso porque os direitos fundamentais, ao menos em sua concepção tradicional, reproduzida nos ordenamentos jurídicos de tradição democrática ocidental, costumam afirmar-se como garantias de livre desenvolvimento da personalidade. É por meio do asseguramento de diferentes liberdades que é dado à pessoa desenvolver a sua personalidade como melhor lhe convém, de acordo com os limites impostos pelo próprio ordenamento jurídico.

Contudo, também há que se reconhecer que o significado dos direitos fundamentais não se esgota na proteção da personalidade individual, ainda que nela adquira grande e destacada parcela de significado, visto que também se dirigem a questões relacionadas à estrutura do ordenamento jurídico, à manutenção da liberdade de concorrência como pressuposto de uma economia próspera ${ }^{44}$ ou, ainda, ao processo de livre formação da opinião, como pressuposto da democracia. ${ }^{45}$

Assim, fala-se em eficácia horizontal quando entram em cena direitos fundamentais que possam incidir nas relações privadas, nas mais diversas formas e modalidades. Nessa espécie de relação, adquirem relevância todos os direitos considerados fundamentais que estejam conectados a um componente de desenvolvimento da personalidade. O foco é a preservação da capacidade de autodeterminação da pessoa, em harmonia com os valores constitucionais, aspecto que deve influenciar teleologicamente a visão atual do Direito, a realizar as metanarrativas modernas de liberdade, igualdade e dignidade. ${ }^{46}$

Fixadas as premissas do estudo, cumpre, agora, direcionar o olhar às duas principais teorias que originaram o debate.

41 CANOTILHO, José Joaquim Gomes. Direito Constitucional e Teoria da Constituição..., p. 1.272; MIRANDA, Jorge. Manual de Direito Constitucional..., p. 320.

42 SARLET, Ingo Wolfgang. Direitos Fundamentais e Direito Privado..., p. 116.

43 RÖTHEL, Anne. Verfassungsprivatrecht aus Richterhand? Verfassungsbindung und Gesetzesbindung der Zivilgerichtsbarkeit. JuS. München und Frankfurt: Beck, 2001, p. 425.

44 MÜLLER-GRAFF, Peter-Christian. Die wettbewerbsverfaßte marktwirtschaft als gemeineuropäisches Verfassungsprinzip? Europarecht. Baden-Baden: Nomos, 1997, p. 433ss.

45 MÜLLER, Jörg Paul. Die Grundrechte der Verfassung und der Persönlichkeitsschutz des Privatrechts. Bern: Stämpfli, 1964, p. 173s.

46 MARQUES, Claudia Lima. Contratos no código de defesa do consumidor..., p. 261. 


\section{TEORIAS SOBRE A EFICÁCIA HORIZONTAL DOS DIREITOS FUNDAMENTAIS}

O reconhecimento de uma eficácia dos direitos fundamentais nas relações privadas não guarda, em si, maiores controvérsias no seio da doutrina constitucional contemporânea. Entretanto, o mesmo não ocorre em relação à intensidade e à forma dessa vinculação, aspectos que costumam dividir a doutrina em um salutar debate. ${ }^{47}$ Dentre outras construções pontuais, três teorias ganharam destaque na doutrina especializada.

\subsection{TEORIA DA EFICÁCIA DIRETA}

A teoria da eficácia direta ou imediata dos direitos fundamentais nas relações privadas foi construída na Alemanha por meio da expressão Unmittelbare Drittwirkung der Grundrechte. Ela ganhou repercussão a partir da obra do jurista Hans Carl Nipperdey, intitulada "A Dignidade Humana", 48 publicada no ano de 1954, na qual restou defendida uma concepção em torno do reconhecimento de uma eficácia direta dos direitos fundamentais nas relações privadas. Essa obra encontrou eco, sobretudo, jurisprudência do Tribunal Federal do Trabalho alemão, órgão no qual Nipperdey atuou como seu primeiro Presidente. Anos mais tarde, em 1960, Walter Leisner publicou uma obra intitulada "Direitos fundamentais e Direito Privado", 49 na qual reforçou a tese de Nipperdey, igualmente orientada ao reconhecimento de uma eficácia direita dos direitos fundamentais nas relações privadas. Desde então, a doutrina reconhece as obras desses dois juristas como os pilares da chamada eficácia horizontal direta. ${ }^{50}$

Em síntese, essa teoria defende que a partir de uma vinculação direta dos particulares aos direitos fundamentais é possível deduzir uma fundamentação direta desses direitos no tráfego jurídico privado, com base nos princípios da dignidade da pessoa humana e da aplicabilidade direta dos direitos fundamentais. ${ }^{51}$ Levando-se em conta a estreita ligação de Nipperdey com o Direito do Trabalho, constata-se que grande parte do desenvolvimento da teoria da eficácia direta encontra-se na fundamentação de decisões dessa natureza.

Nessa linha, a teoria da eficácia direta sindicaliza que os direitos fundamentais não necessitam, em princípio, de transformações para serem aplicados no âmbito das relações privadas, assumindo, assim, a função de direitos de defesa oponíveis contra outros particulares, de modo que os indivíduos podem invocar os seus direitos subjetivos fundamentais também perante outros sujeitos privados, em termos semelhantes àqueles que os opunham contra o Estado. ${ }^{52}$ Desse modo, certos direitos fundamentais possuem eficácia absoluta ou uma eficácia normativa direta em sua qualidade como

\footnotetext{
47 Vide DUQUE, Marcelo Schenk. Eficácia Horizontal dos Direitos Fundamentais..., p. 57ss.

48 NIPPERDEY, Hans Carl. Die Würde des Menschen..., p. 1ss.

49 LEISNER, Walter. Grundrechte und Privatrecht. München: Beck, 1960, p. 1ss.

50 SARLET, Ingo Wolfgang. Direitos Fundamentais e Direito Privado..., p. 121ss.

51 DUQUE, Marcelo Schenk. Eficácia Horizontal dos Direitos Fundamentais..., p.58ss.

52 NIPPERDEY, Hans Carl. Die Würde des Menschen..., p. 18ss.
} 
Direito Constitucional vinculativo e objetivo, que revoga, modifica, complementa ou cria novas determinações de Direito Privado, dentro de uma ideia maior de conceber os direitos fundamentais como princípios ordenadores da vida social. ${ }^{53}$

Na doutrina pátria, a aceitação de uma eficácia direta dos direitos fundamentais nas relações privadas ganhou espaço pelos escritos de Ingo Wolfgang Sarlet, sob o ponto de vista de que a eficácia direta dos direitos fundamentais nas relações entre particulares, estejam eles ou não em pé de igualdade, encontra fundamento junto ao princípio da dignidade humana, já que na esfera desse conteúdo são, em tese, irrenunciáveis. ${ }^{54} \mathrm{~A}$ partir daí, outros autores começaram a defender modelos semelhantes, ainda que com variações pontuais. ${ }^{55}$

Com efeito, um modelo de eficácia direta dos direitos fundamentais nas relações privadas não foi seguido pela doutrina alemã no pós II Guerra, em especial a partir da atuação do Tribunal Constitucional Federal, que se aliou à teoria da eficácia indireta, como se verá adiante. De fato, a teoria da eficácia direta, ao menos na forma como foi originalmente concebida, restou abandonada por juristas de diferentes gerações, ${ }^{56}$ sendo considerada minoritária na maioria dos países onde se verifica um tratamento sistemático do tema. ${ }^{57}$ Dentre outros argumentos, o motivo preponderante que levou ao rechaço dessa concepção foi sua incompatibilidade com o princípio da autonomia privada, de modo a desvirtuar o próprio significa do Direito Privado como um todo. ${ }^{58}$

53 NIPPERDEY, Hans Carl. Grundrechte und Privatrecht. In: NIPPERDEY, Hans Carl. (Hrsg.). Festschrift für Erich Molitor zum 75. Geburtstag. München und Berlin: Beck Verlagsbuchhandlung, 1962, p. 24.

54 SARLET, Ingo Wolfgang. Direitos Fundamentais e Direito Privado..., p. 157.

55 CASTRO, Carlos Roberto Siqueira. Aplicação dos Direitos Fundamentais às Relações Privadas. In: PEREIRA, Antônio Celso Alves; ALBUQUERQUE MELLO, Celso Renato Duvivier de (Orgs.). Estudos em Homenagem a Carlos Alberto Menezes Direito. Rio de Janeiro - São Paulo: Renovar, 2003, p. 238s; GEBRAN NETO, João Pedro. A aplicação imediata dos direitos e garantias individuais, p. 165; SARMENTO, Daniel. Direitos Fundamentais e Relações Privadas..., p. 279ss; SOMBRA, Thiago Luís Santos. A Eficácia dos Direitos Fundamentais nas Relações Jurídico-Privadas. A identificação do contrato como ponto de encontro dos direitos fundamentais. Porto Alegre: Fabris, 2004, p. 170; 202; STEINMETZ, Wilson Antônio. A Vinculação dos Particulares a Direitos Fundamentais..., p. 271ss; 374; TEPEDINO, Gustavo. A incorporação dos direitos fundamentais pelo ordenamento brasileiro: sua eficácia nas relações jurídicas privadas. Revista da Ajuris. Porto Alegre: Associação dos Juízes do Rio Grande do Sul, n. 100, dezembro 2005, p. 153ss; VALE, André Rufino do. A eficácia dos direitos fundamentais nas relações privadas. Porto Alegre: Sergio Antonio Fabris, 2004, p. 178ss.

56 DÜRIG, Günter. Freizügigkeit. In: NEUMANN, Franz L.; NIPPERDEY, Hans Carl; SCHEUNER, Ulrich (Hrsg.). Die Grundrechte. Handbuch der Theorie und Praxis der Grundrechte (HGrR). Band II. Duncker-Humblot: Berlim, 1954, p. 525; ERICHSEN, Hans-Uwe. Staatsrecht und Verfassungsgerichtsbarkeit. 3., völlig neu bearbeitete Auflage. München: Beck, 1982, Vol. I., p. 43; HÄBERLE, Peter. Die Wesensgehaltgarantie des Artikel 19 Absatz 2 Grundgesetz: zugleich ein Beitrag zum institutionellen Verständnis der Grundrechte und zur Lehre vom Gesetzesvorbehalt. 3., stark erw. Auflage. Heidelberg: Müller, 1983, p. 192ss; CANARIS, Claus-Wilhelm. Grundrechte und Privatrecht. Archiv für die civilistische Praxis (AcP), Band 184. Tübingen: Mohr, 1984, p. 202ss; MAUNZ, Theodor; ZIPPELIUS, Reinhold. Deutsches Staatsrecht. 27., neubearbeitete Auflage. München: Beck, 1988, p. 138; HERZOG, Roman. Das Bundesverfassungsgericht und die Anwendung einfachen Gesetzesrechts. In: MAURER, Hartmut (Hrsg.). Das Akzeptierte Grundgesetz. Festschrift für Günter Dürig zum 70. Geburtstag. München: Beck, 1990, p. 436s; GRIMM, Dieter. Das Grundgesetz nach vierzig Jahren. In: GRIMM, Dieter. Die Zukunft der Verfassung. Frankfurt: Suhrkamp, 1991, p. 1.308; HESSE, Konrad. Grundzüge des Verfassungsrechts der Bundesrepublik Deutschland..., Rdnr. 355; DREIER, Horst. Grundgesetz Kommentar. Grundgesetz Kommentar. In: DREIER, Horst (Hrsg.). Grundgesetz Kommentar . 2. Auflage. Tübingen: Mohr, Band I, 2004 (Vorb. Art. 1), Rdnr. 98.

57 SILVA, Virgílio Afonso da. A Constitucionalização do Direito..., p. 94.

58 MENDES, Gilmar Ferreira. Direitos fundamentais e controle de constitucionalidade..., p. 124ss. 
A questão preponderante levantada pela doutrina foi o fato de que todos os particulares são igualmente titulares de direitos fundamentais, razão pela qual uma mediação legislativa ou, eventualmente, judicial, faz-se necessária para definir os limites da liberdade de cada um, sob pena de se incorrer em consideráveis problemas de índole prática, no curso de relações privadas. ${ }^{59}$ Entre nós, observou-se ainda o risco de uma constitucionalização irrestrita de todo o Direito, relegando o âmbito do Direito Privado a segundo plano bem como a ampliação da atuação do Supremo Tribunal Federal a uma espécie de corte de revisão, o que não seria desejável, ${ }^{60}$ além de outras críticas pontuais.

O debate rumou para a construção de que a autonomia privada encontra amparo na garantia constitucional de livre desenvolvimento da personalidade, amparada por diferentes direitos de liberdade, aliada ao fato de que essa garantia não vige ilimitadamente no ordenamento jurídico. Significa dizer que a autonomia privada, assim como qualquer outra norma do ordenamento jurídico, não pode ser ilimitada, ${ }^{61}$ de acordo com a noção de que não existem direitos absolutos. ${ }^{62}$ Condiciona, em contrapartida, a aplicação dos direitos fundamentais nas relações privadas, sob pena de ser vulnerada em seu conteúdo essencial, ${ }^{63}$ não admitindo, assim, um modelo que preveja a vinculação ampla e direta dos particulares aos direitos fundamentais. Inegavelmente, a autonomia tem que sempre permanecer referida ao seu núcleo, que é a configuração vital auto responsável da personalidade. A partir dessa configuração é que ela recebe medida e também os seus limites. ${ }^{64}$

Sem embargo, é possível visualizar a existência de determinados direitos fundamentais no ordenamento jurídico, cuja estrutura permitiria, em tese, gerar uma eficácia direta no curso de relações privadas. No caso brasileiro, essa possibilidade pode ser verificada, particularmente, à luz dos direitos trabalhistas previstos na Constituição de $1988,{ }^{65}$ ainda que se possa discutir em qual extensão. É fato que a partir do momento em que o legislador constituinte optou por incorporar grande parte de direitos de natureza trabalhista, a Constituição passa a abrir espaço para uma eficácia direta desses direitos nas relações de trabalho, já que várias dessas garantias adquirem expressão prática em relações de natureza privada.

Para além dos direitos de natureza trabalhista poderia cogitar-se de outros, como, por exemplo, os direitos de reunião $\left(5 .^{\circ}, \mathrm{XVI}\right)$ e de associação $\left(5 .^{\circ}, \mathrm{XVII}\right)$. Trata-se de direitos que possuem significado estreito nas relações privadas, razão pela qual se podem verificar casos onde uma eficácia direta seria

59 A crítica detalhada encontra-se em DUQUE, Marcelo Schenk. Eficácia Horizontal dos Direitos Fundamentais..., p. 70ss.

60 TAVARES, André Ramos. Curso de Direito Constitucional. 8 ed. São Paulo: Saraiva, 2010, p. 527.

61 LARENZ, Karl. LARENZ, Karl. Allgemeiner Teil des deutschen Bürgerlichen Rechts. 7. neuberabeitete Auflage. München: Beck, 1989, § 2. ${ }^{\circ}$, II, p. 42.

62 DUQUE, Marcelo Schenk. Curso de Direitos Fundamentais: teoria e prática. São Paulo: Revista dos Tribunais, 2014, p. 311ss.

63 MIRANDA, Jorge. Manual de Direito Constitucional. p. 323 s.

64 MÜLLER, Jörg Paul. Die Grundrechte der Verfassung und der Persönlichkeitsschutz des Privatrechts..., p. 177.

65 STEINMETZ, Wilson Antônio. A Vinculação dos Particulares a Direitos Fundamentais..., p. 277ss. 
admissível. ${ }^{66}$ Todavia, há que se perceber que mesmo a possibilidade de eficácia direta desses direitos deve ser vista com certo grau de cautela. Isso porque o gozo efetivo dessas garantias, não obstante estarem previstas na Constituição, acaba por depender, na prática, de regulamentação precisa pela legislação ordinária, com vistas a delimitar não apenas a medida de sua extensão em casa caso, mas também o modo como elas são implementadas, razão pela qual a legislação ordinária desempenha um papel fundamental na concretização desses direitos e, nesse sentido, na sua efetividade para o mundo jurídico.

\subsection{TEORIA DA EFICÁCIA INDIRETA}

A teoria da eficácia indireta ou mediata (Mittelbare Drittwirkung), ainda que conste com precursores em diferentes sentidos, ${ }^{67}$ é uma criação atribuída ao jurista alemão Günter Dürig ${ }^{68}$ que, no ano de 1954, defendeu a impossibilidade de contratos privados excluírem a possibilidade de livre circulação de uma das partes contratantes. Dürig construiu um ponto de vista baseado na concepção de que a eficácia dos direitos fundamentais nas relações privadas ocorre de forma indireta, por meio da interpretação das cláusulas gerais do Direito Civil passíveis e carentes de preenchimento valorativo. ${ }^{69}$

A oposição dessa teoria à da eficácia direta reside no fato de que as posições asseguradas pelos direitos fundamentais e dirigidas contra o Estado não podem transferir-se de modo direto para as relações entre particulares, tendo em vista que a força conformadora dos direitos fundamentais ocorre por meio da legislação infraconstitucional. O mecanismo está na constatação de que os direitos fundamentais, em maior ou em menor grau, devem concretizar os conceitos jurídicos indeterminados e as cláusulas gerais como linhas diretivas de interpretação, clarificando-as, acentuando ou desacentuando determinados elementos do seu conteúdo ou, em casos extremos, colmatando e preenchendo as lacunas. ${ }^{70}$

Dürig centrou o seu argumento na constatação de que o dever de respeito à dignidade humana é a norma central do ordenamento jurídico, a partir da qual se gera um efeito de irradiação. Esse efeito de irradiação concretiza-se por meio de diversos direitos fundamentais, que por um lado garantem a liberdade e a autonomia do particular contra o Estado como direitos subjetivos e, por outro, desenvolvem efeitos também no tráfego jurídico privado, corolário de preservação da unidade da moral jurídica, como consequência do próprio respeito à dignidade humana. ${ }^{71}$

66 DIEDERICHSEN Uwe. Die Rangverhältnisse zwischen den Grundrechten und dem Privatrecht. In: STARCK, Christian (Hrsg.). Rangordnung der Gesetze. 7 Symposion der Kommission „Die Funktion des Gesetzes in Geschichte und Gegenwart" am 22. und 23. April 1994. Göttingen: Vandenhoeck \& Ruprecht, 1995, C, p. 110, Rdnr. 23; entre nós, vide SILVA, Virgílio Afonso da. A Constitucionalização do Direito..., p. 86s. DUQUE, Marcelo Schenk. Eficácia Horizontal dos Direitos Fundamentais..., p. 204ss.

68 DÜRIG, Günter. Freizügigkeit..., p. 525.

69 DÜRIG, Günter. Grundrechte und Zivilrechtsprechung. In: Maunz, Theodor (Hrsg.). Vom Bonner Grundgesetz zur gesamtdeutschen Verfassung - Festschrift zum 75. Geburtstag von Hans Nawiasky. München: Isar, 1956, p. 176s.

70 DÜRIG, Günter. Grundrechte und Zivilrechtsprechung..., p. 177s.

71 DÜRIG, Günter. Grundgesetz Kommentar (Art. 1 GG). In: MAUNZ, Theodor; DÜRIG, Günter; et. al. Grundgesetz Kommentar. München: Beck, Band I, 1958, Rdnr. 130ss. 
Essa construção ganhou força a partir da referida sentença Lüth, ocasião em que o Tribunal Constitucional Federal alemão rechaçou, expressamente, um modelo de eficácia direta, nitidamente inspirado nos escritos de Dürig, ao sugerir que a eficácia dos direitos fundamentais nas relações privadas ocorre de modo indireto. Nas palavras do Tribunal, "no Direito Civil o conteúdo jurídico dos direitos fundamentais desenvolve-se indiretamente por meio das prescrições jurídico-privadas". ${ }^{72}$ O grande traço da sentença Lüth foi o panorama que evidenciou a chamada eficácia irradiante dos direitos fundamentais) ${ }^{73}$, como expressão de uma ordem de valores jurídico-objetiva, que irradia efeitos para todos os âmbitos jurídicos ${ }^{74}$, entendimento que influenciou várias decisões posteriores. ${ }^{75}$

O núcleo da teoria da eficácia indireta deixa-se reconduzir à constatação de que a influência dos direitos fundamentais sobre o Direito Privado é, em primeiro lugar, uma tarefa do legislador ordinário, vinculado, por sua vez, aos direitos fundamentais, a quem cabe concretizar o conteúdo jurídico desses direitos, demarcando as posições dos sujeitos privados garantidas pela constituição. A ideia central é que cabe ao legislador a tarefa precípua de determinar o equilíbrio entre o respeito à liberdade individual e a vigência efetiva dos direitos fundamentais. ${ }^{76}$

A concepção esposada por Günter Dürig ${ }^{77}$ revela que junto à mediação legislativa - e de certa forma como resposta a eventuais insuficiências desse próprio procedimento de recepção - existe uma segunda via de penetração (indireta) dos direitos fundamentais no âmbito do Direito Privado. Essa se dá por meio da mediação do Poder Judiciário, ${ }^{78}$ fundamentada na circunstância de que os juízes, por um mandamento constitucional, podem examinar se as disposições de Direito Civil que devem aplicar estão influenciadas pelos direitos fundamentais na forma de critérios valorativos, que se realizam, sobretudo, mediante as disposições de Direito Privado que contêm um direito imperativo e que, portanto, formam parte da ordem pública em sentido amplo. Fala-se, aqui, de princípios, que por fundamentos em prol do interesse geral, devem ser vinculantes para a configuração das relações jurídicas entre particulares e que, por isso, estão subtraídos do domínio da autonomia da vontade. ${ }^{79}$

As maiores críticas dirigidas à teoria da eficácia indireta residem no fato de que ela não é

72 BVerfGE 7, 198 (LS 2).

73 ALEXY, Robert. Theorie der Grundrechte..., p. 477ss.

74 HESSE, Konrad. Verfassungsrecht und Privatrecht. Heidelberg: Müller, 1988, p. 23.

75 DUQUE, Marcelo Schenk. Eficácia Horizontal dos Direitos Fundamentais..., p. 234ss.

76 ALFARO AGUILA-REAL, Jesús. Autonomia Privada y Derechos Fundamentales. Anuário de Derecho Civil. Madrid, tomo XLVI, fascículo 1, jan. - mar. 1993, p. 65.

77 DÜRIG, Günter. Grundrechte und Zivilrechtsprechung..., p. 176ss.

78 A atuação do poder judiciário, de forma supletiva, como veículo mediador na influência dos direitos fundamentais na órbita privada é, em geral, aceita pela doutrina. Nesse sentido, por todos, vide STERN, Klaus. Das Staatsrecht der Bundesrepublik Deutschland..., p. 1.551ss; entre nós, vide SARLET, Ingo Wolfgang. Direitos Fundamentais e Direito Privado..., p. 142ss; MENDES, Gilmar Ferreira. Direitos Fundamentais: eficácia das garantias constitucionais nas relações privadas. Análise da jurisprudência da Corte Constitucional Alemã. Revista dos Tribunais. Cadernos de Direito Constitucional e Ciência Política. São Paulo: IBDC, n. ${ }^{\circ} 27$, abr.-jun. 1999, p. 43. BVerfGE, 7, 198 (206). 
capaz de desenvolver a máxima eficácia dos direitos fundamentais no curso de relações privadas. Dentre outros pontos, argumentou-se que o fundamento básico dessa teoria resume-se à concepção dos direitos fundamentais como linhas diretivas para a interpretação, bem como critérios de concretização para o Direito Privado ${ }^{80}$, o que estaria aquém do significado desses direitos. De outra banda, ponderou-se que a teoria da eficácia indireta, ao propor que em um primeiro momento o legislador e, supletivamente, o juiz devam intermediar a aplicação das leis privadas às relações entre particulares, peca por confundir a questão da vinculação dos sujeitos privados com a vinculação do Poder Público. ${ }^{81}$

\subsection{POSSÍVEL EQUIVALÊNCIA DE RESULTADOS ENTRE AS TEORIAS DIRETA E INDIRETA}

A doutrina, na busca de uma solução conciliatória para o debate entre as teorias que investigam a eficácia horizontal dos direitos fundamentais, teceu esforços para sustentar a existência de uma espécie de uma equivalência de resultados entre as teorias. Buscou-se, com isso, uma aplicação conjunta, e não excludente, de diferentes concepções que buscam visualizar o problema. ${ }^{82}$ Isso se deu no curso de uma espécie de modelo combinado ou integrador, que agrega elementos das teorias direta e indireta, a partir de um modelo de três níveis para fundamentar a eficácia dos direitos fundamentais nas relações privadas: o dos deveres do Estado; o dos direitos do particular frente ao Estado; e o das relações jurídicas entre sujeitos de direito privado propriamente ditas ${ }^{83}$.

O primeiro nível é marcado pelo dever do Estado. Aqui, os tribunais são obrigados a observar a ordem de valores objetiva dos direitos fundamentais, no sentido da doutrina de Dürig e da fundamentação expressa na sentença Lüth, de modo que ao primeiro nível atribui-se uma eficácia indireta dos direitos fundamentais nas relações privadas ${ }^{84}$. Aqui, é dever do Estado respeitar a ordem de valores da Constituição, tanto na legislação infraconstitucional quanto na aplicação judicial do direito ${ }^{85}$.

Já o segundo nível é marcado pela constatação de direitos do particular frente ao Estado na forma de direitos de defesa e de proteção. Aqui o particular tem o direito de exigir que os tribunais considerem em devida medida os direitos fundamentais dos quais é titular, no curso de suas decisões sobre controvérsias privadas. De acordo com a configuração do caso concreto, os tribunais (e com isso o Estado) têm duas possibilidades: permitir uma determinada atuação jurídico-privada, hipótese em que uma proibição representaria uma violação de um ou mais direitos fundamentais na acepção de direitos de defesa; ou proibir uma determinada atuação privada alheia, hipótese em que a respectiva

80 CANARIS, Claus-Wilhelm. Grundrechte und Privatrecht..., p. 224.

81 SARLET, Ingo Wolfgang. Direitos Fundamentais e Direito Privado..., p. 142s.

82 NARANJO DE LA CRUZ, Rafael. Los límites de los derechos fundamentales em las relaciones entre particulares: la buena fe. Madrid: Centro de Estudios Políticos y Constitucionales, 2000, p. 242ss.

83 ALEXY, Robert. Theorie der Grundrechte..., p. 484ss. Entre nós, vide STEINMETZ, Wilson Antônio. A Vinculação dos Particulares a Direitos Fundamentais..., p. 181.

84 ALEXY, Robert. Theorie der Grundrechte..., 1994, p. 485.

85 SILVA, Virgílio Afonso da. A Constitucionalização do Direito..., p. 145. 


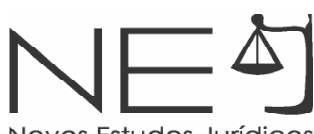

concessão implicaria um dever de proteção jurídico-fundamental ${ }^{86}$. Nesse segundo nível, Alexy conecta as dimensões de defesa e de proteção, a partir do instante em que direciona uma pretensão do cidadão de defesa ou de proteção respectivamente, contra a jurisdição em matéria civil ${ }^{87}$. Aqui se faz referência, de certa maneira, à teoria dos deveres de proteção do Estado que, em última análise, também se constitui em um modelo de eficácia indireta, já que carente de intermediação legislativa.

Por fim, o terceiro nível é caracterizado pelas relações jurídicas entre sujeitos de direito privado, essas compreendidas por determinados direitos e não-direitos, liberdades e não-liberdades, competências e não competências, onde se atribui uma eficácia direta dos direitos fundamentais nas relações privadas ${ }^{88}$. O argumento, para tanto, é que a partir do reconhecimento de uma eficácia dos direitos fundamentais nas relações privadas se fazem presentes posições jurídico-fundamentais que, de outra forma, não existiriam ${ }^{89}$.

Interessante notar que Alexy reconhece que não se pode renunciar à função mediadora do Direito Privado para a solução de controvérsias que digam respeito à influência dos direitos fundamentais nas relações privadas. Nesse sentido, reconhece que as doutrinas da eficácia direta e indireta acabam, de uma forma ou de outra, por transpor-se nesse terceiro nível, de modo que os seus respectivos limites acabam por esvaecer ${ }^{90}$. O que não fica claro, nesse modelo, é se a função mediadora do direito privado para a solução de controvérsias que digam respeito à influência dos direitos fundamentais nas relações privadas mostra-se imprescindível, como é que tais limites acabam por se esvaecer? O problema de se conceber uma Drittwirkung direta, seja em que nível for, é que dela deve resultar, necessariamente, uma vigência de direitos fundamentais geral, a partir da qual resultam não apenas direitos, mas também deveres de todos, oponíveis contra todos ${ }^{91}$. Compatibilizar diferentes interesses, em um cenário de igualdade de direitos, torna-se uma tarefa de grande complexidade. De fato, não se nota na doutrina uma repercussão plenamente favorável a esse modelo combinado ${ }^{92}$, talvez pela circunstância de reunir em um único modelo problemas comuns apontados aos demais ${ }^{93}$.

Certo é que o debate persiste e passou a ser direcionado para outros aspectos, visando a compatibilizar a proteção dos direitos fundamentais nas relações privadas, com os diferentes bens e institutos protegidos pelo ordenamento jurídico-constitucional. Abre-se caminho para a análise

86 ALEXY, Robert. Theorie der Grundrechte..., p. 488s.

87 RUFFERT, Matthias. Vorrang der Verfassung und Eigenständigkeit des Privatrechts. Eine verfassungsrechtliche Untersuchung zur Privatrechtswirkung des Grundgesetzes. Tübingen: Mohr Siebeck, 2001, p. 19.

88 ALEXY, Robert. Theorie der Grundrechte..., p. 490s.

89 ALEXY, Robert. Theorie der Grundrechte..., p. 490.

90 ALEXY, Robert. Theorie der Grundrechte..., p. 492s.

91 BADURA, Peter. Persönlichkeitsrechtliche Schutzpflichten des Staates im Arbeitsrecht. In: GAMILLSCHEG, Franz; RÜTHERS, Bernd; STAHLHACKE, Eugen. (Hrsg.). Festschrift für Karl Molitor zum 60. Geburtstag. München: Beck, 1988, p. 5.

92 Entre nós, ele é defendido, como "ponto de partida" por SILVA, Virgílio Afonso da. A Constitucionalização do Direito..., p. 143ss.

93 LANGNER, Thomas. Die Problematik der Geltung der Grundrechte zwischen Privaten. Frankfurt: Peter Lang, 1998, p. 82, ponderando que o modelo em três níveis mostra-se como não significativo do ponto de vista prático. 
futura da teoria dos deveres de proteção do Estado que, pelas delimitações da análise ora proposta, deixa de ser, por ora, apresentada. Esse será o próximo ponto a ser focado em considerações futuras.

\section{CONSIDERAÇÕES FINAIS}

A temática da eficácia horizontal dos direitos fundamentais envolve uma complexidade inegavelmente superior à tradicional eficácia vertical, que diz respeito à vinculação dos órgãos estatais. Isso porque trata da delimitação de espaços de liberdade, garantidos a todos os titulares de direitos fundamentais. Não é uma tarefa simples, delimitar com precisão até que ponto um particular poderá recorrer a um direito fundamental para justificar a sua liberdade de ação, em face de outro particular que, por sua vez, é titular dos mesmos direitos, e vê a sua ação restringida por terceiros.

A doutrina alemã construiu uma sólida argumentação, não só para descrever o problema, quanto para propor soluções. Quando se verifica a forma pela qual a temática da eficácia horizontal foi importada para o Brasil, constata-se uma considerável diferença de concepções em relação à abordagem germânica. Enquanto no Brasil geralmente se defende uma eficácia geral e imediata da maioria dos direitos fundamentais nas relações privadas, os estudiosos alemães tendem a refutar essa possiblidade, pela falta de critérios sólidos capazes de definir os limites da liberdade de ação geral de cada particular. Optam, assim, por uma mediação legislativa, que traduza o significado dos direitos fundamentais nas relações privadas, o que pode se efetivar de diferentes formas. $\mathrm{O}$ debate está aberto e longe do fim.

\section{REFERÊNCIAS DAS FONTES CITADAS}

ALEXY, Robert. Theorie der Grundrechte. Baden-Baden: Suhrkamp, 1994.

ALEXY, Robert. Theorie der juristischen Argumentation. Die Theorie des rationalen Diskurses als Theorie der juristischen Begründung. 2. Auflage. Frankfurt am Main: Suhrkamp, 1990.

ALFARO AGUILA-REAL, Jesús. Autonomia Privada y Derechos Fundamentales. Anuário de Derecho Civil. Madrid, tomo XLVI, fascículo 1, jan. - mar. 1993.

ARENDT, Hannah. A condição humana. 10. ed. Rio de Janeiro: Forense Universitária, 2004.

ARENDT, Hannah. Eichmann em Jerusalém: um relato sobre a banalidade do mal. Traduzido por José Rubens Siqueira. São Paulo: Cia. das Letras, 1999.

ÁVILA, Humberto. Segurança Jurídica. Entre permanência, mudança e realização no Direito Tributário. São Paulo: Malheiros, 2011.

BADURA, Peter. Persönlichkeitsrechtliche Schutzpflichten des Staates im Arbeitsrecht. In: GAMILLSCHEG, Franz; RÜTHERS, Bernd; STAHLHACKE, Eugen. (Hrsg.). Festschrift für Karl Molitor zum 60. Geburtstag. München: Beck, 1988.

BARROSO, Luís Roberto. Curso de Direito Constitucional Contemporâneo: os conceitos fundamentais e a construção do novo modelo. 2 ed. São Paulo: Saraiva.

BONAVIDES, Paulo. Curso de Direito Constitucional. 12.ed. rev. São Paulo: Malheiros, 2002. 
BRANCO, Paulo Gustavo Gonet. In: MENDES, Gilmar Ferreira; BRANCO, Paulo Gustavo Gonet. Curso de Direito Constitucional. 10. ed. São Paulo: Saraiva, 2015.

BYDLINSKI, Franz. Kriterien und Sinn der Unterscheidung von Privatrecht und öffentlichem Recht. Archiv für die civilistische Praxis (AcP), Band 194. Tübingen: Mohr, 1994.

CANARIS, Claus-Wilhelm. Grundrechte und Privatrecht. Archiv für die civilistische Praxis (AcP), Band 184. Tübingen: Mohr, 1984.

CANARIS, Claus-Wilhelm. Grundrechte und Privatrecht. Eine Zwischenbilanz. Berlin - New York: Walter de Gruyter, 1999.

CANOTILHO, José Joaquim Gomes. Civilização do Direito Constitucional ou Constitucionalização do Direito Civil? A eficácia dos direitos fundamentais na ordem jurídico-civil no contexto do direito pós-moderno. In: GRAU, Eros Roberto; GUERRA FILHO, Willis Santiago (orgs.). Direito Constitucional. Estudos em homenagem a Paulo Bonavides. São Paulo: Malheiros, 2001.

CANOTILHO, José Joaquim Gomes. Direito Constitucional e Teoria da Constituição. 6.ed. Coimbra: Almedina, 2002.

CASTRO, Carlos Roberto Siqueira. Aplicação dos Direitos Fundamentais às Relações Privadas. In: PEREIRA, Antônio Celso Alves; ALBUQUERQUE MELLO, Celso Renato Duvivier de (Orgs.). Estudos em Homenagem a Carlos Alberto Menezes Direito. Rio de Janeiro - São Paulo: Renovar, 2003.

CHEREDNYCHENKO, Olha O. Fundamental Rights. Contract Law and the Protection of the Weaker Party. A Comparative Analysis of the Constitutionalisation of Contract Law, with Emphasis on Risky Financial Transactions. München: Sellier European Law Publishers, 2007.

DIEDERICHSEN Uwe. Die Rangverhältnisse zwischen den Grundrechten und dem Privatrecht. In: STARCK, Christian (Hrsg.). Rangordnung der Gesetze. 7 Symposion der Kommission „Die Funktion des Gesetzes in Geschichte und Gegenwart" am 22. und 23. April 1994. Göttingen: Vandenhoeck \& Ruprecht, 1995.

DIMOULIS, Dimitri; MARTINS, Leonardo. Teoria Geral dos Direitos Fundamentais. 3 ed. São Paulo: Revista dos Tribunais.

DREIER, Horst. Grundgesetz Kommentar. Grundgesetz Kommentar. In: DREIER, Horst (Hrsg.). Grundgesetz Kommentar . 2. Auflage. Tübingen: Mohr, Band I, 2004.

DUQUE, Marcelo Schenk. Curso de Direitos Fundamentais: teoria e prática. São Paulo: Revista dos Tribunais, 2014.

DUQUE, Marcelo Schenk. Eficácia Horizontal dos Direitos Fundamentais e Jurisdição Constitucional. 2 ed. revista e ampliada. São Paulo: Editora dos Editores, 2019.

DÜRIG, Günter. Freizügigkeit. In: NEUMANN, Franz L.; NIPPERDEY, Hans Carl; SCHEUNER, Ulrich (Hrsg.). Die Grundrechte. Handbuch der Theorie und Praxis der Grundrechte (HGrR). Band II. Duncker-Humblot: Berlim, 1954.

DÜRIG, Günter. Grundgesetz Kommentar (Art. 1 GG). In: MAUNZ, Theodor; DÜRIG, Günter; et. al. Grundgesetz Kommentar. München: Beck, Band I, 1958.

DÜRIG, Günter. Grundrechte und Zivilrechtsprechung. In: Maunz, Theodor (Hrsg.). Vom Bonner Grundgesetz zur gesamtdeutschen Verfassung - Festschrift zum 75. Geburtstag von Hans Nawiasky. München: Isar, 1956.

ENDERS, Christoph. Die Menschenwürde in der Verfassungsordnung. Zur Dogmatik des Art. 1 GG. Tübingen: Mohr, 1997.

ERICHSEN, Hans-Uwe. Allgemeine Handlungsfreiheit. In: ISENSEE, Josef; KIRCHHOF, Paul. (Hrsg.). Handbuch des Staatsrechts der Bundesrepublik Deutschland (HStR). Zweite, durchgesehene Auflage. Heidelberg: 
Müller, Band VI.

ERICHSEN, Hans-Uwe. Staatsrecht und Verfassungsgerichtsbarkeit. 3., völlig neu bearbeitete Auflage. München: Beck, 1982, Vol. I.

FERREIRA FILHO, Manoel Gonçalves. Aspectos do direito constitucional contemporâneo. 3. ed. São Paulo: Saraiva, 2011, p. 50.

FERREIRA FILHO, Manoel Gonçalves. Curso de Direito Constitucional. 36. ed. São Paulo: Saraiva, 2010.

GEBRAN NETO, João Pedro. A aplicação imediata dos direitos e garantias individuais: a busca de uma exegese emancipatória. São Paulo: Editora Revista dos Tribunais, 2002.

GRIMM, Dieter. Das Grundgesetz nach vierzig Jahren. In: GRIMM, Dieter. Die Zukunft der Verfassung. Frankfurt: Suhrkamp, 1991.

GRIMM, Dieter. Entstehungs- und Wirkungsbedingungen des modernen Konstitutionalismus. In: GRIMM, Dieter. Die Zukunft der Verfassung. Frankfurt am Main: Suhrkamp, 1991.

HÄBERLE, Peter. Die Wesensgehaltgarantie des Artikel 19 Absatz 2 Grundgesetz: zugleich ein Beitrag zum institutionellen Verständnis der Grundrechte und zur Lehre vom Gesetzesvorbehalt. 3., stark erw. Auflage. Heidelberg: Müller, 1983.

HÄBERLE, Peter. Grundrechte im Leistungsstaat. Veröffentlichungen der Vereinigung der Deutschen Staatsrechtslehrer (VVDStRL), Band 30. Berlin, New York: Walter de Gruyter, 1972.

HERZOG, Roman. Das Bundesverfassungsgericht und die Anwendung einfachen Gesetzesrechts. In: MAURER, Hartmut (Hrsg.). Das Akzeptierte Grundgesetz. Festschrift für Günter Dürig zum 70. Geburtstag. München: Beck, 1990.

HESSE, Konrad. Bestand und Bedeutung der Grundrechte in der Bundesrepublik Deutschland. Europäische Grundrechte Zeitschrift (EuGRZ). Kehl - Straßburg: Engel, 1978.

HESSE, Konrad. Grundzüge des Verfassungsrechts der Bundesrepublik Deutschland. Neudruck der 20. Auflage. Heidelberg: Müller, 1999.

HESSE, Konrad. Verfassungsrecht und Privatrecht. Heidelberg: Müller, 1988.

ISENSEE, Josef. Das Grundrecht als Abwehrrecht und staatliche Schutzpflicht. In: ISENSEE, Josef; KIRCHHOF, Paul. (Hrsg.). Handbuch des Staatsrechts der Bundesrepublik Deutschland (HStR). Heidelberg: Müller, Band V.

JAYME, Erik. Identité culturelle et intégration: lê droit internationale prive postmoderne. Cours general de droit international prive. In: Recueil des Cours. Collected Courses of the Hague Academy of International Law, 1995, Tome 251. Martinus Nijhoff Publishers: The Hague/Boston/London, 1996.

JELLINEK, Georg. System der Subjektiven Öffentlichen Rechte. 2. Auf. Tübingen: Mohr, 1919.

LAFER, Celso. A reconstrução dos direitos humanos: um diálogo com o pensamento de Hannah Arendt. São Paulo: Companhia da Letras, 1988.

LANGNER, Thomas. Die Problematik der Geltung der Grundrechte zwischen Privaten. Frankfurt: Peter Lang, 1998.

LARENZ, Karl. LARENZ, Karl. Allgemeiner Teil des deutschen Bürgerlichen Rechts. 7. neuberabeitete Auflage. München: Beck, 1989.

LEISNER, Walter. Grundrechte und Privatrecht. München: Beck, 1960.

LÜCKE, Jörg. Die Drittwirkung der Grundrechte an Hand des Art. 19 Abs. 3 GG. Zur horizontalen Geltung der Grundrechte in neuer Sicht. Juristen Zeitung, 1999, n. ${ }^{\circ} 08$. 
MARQUES, Claudia Lima. Sugestões para uma lei sobre o tratamento do superendividamento de pessoas físicas em contratos de crédito ao consumo: proposições com base em pesquisa empírica de 100 casos no Rio Grande do Sul. RDC. São Paulo: Revista dos Tribunais, n. 55, jul.-set. 2005.

MARQUES, Claudia Lima. Contratos no código de defesa do consumidor: o novo regime das relações contratuais. 8. ed. São Paulo: Revista dos Tribunais, 2016.

MARQUES, Claudia Lima. CAVALLAZZI, Rosângela Lunardelli. Introdução. In: MARQUES, Claudia Lima; CAVALLAZZI, Rosângela Lunardelli (Coord.). Direitos do Consumidor Endividado. Superendividamento e crédito. São Paulo: Revista dos Tribunais, 2006.

MARTÍNEZ, Gregorio Peces-Barba. Curso de derechos fundamentales - Teoria general. Madrid: Universidad Carlos III, 1995.

MARTINY, Anke. Die Verbraucher als zersplitterte Gegenmacht im Markt. In: PIEPENBROCK, Hartwig; SCHROEDER, Conrad (Hrsg.). Verbraucherpolitik Kontrovers. Köln: Deutscher Instituts-Verlag, 1987.

MAUNZ, Theodor; ZIPPELIUS, Reinhold. Deutsches Staatsrecht. 27., neubearbeitete Auflage. München: Beck, 1988.

MENDES, Gilmar Ferreira. Direitos Fundamentais: eficácia das garantias constitucionais nas relações privadas. Análise da jurisprudência da Corte Constitucional Alemã. Revista dos Tribunais. Cadernos de Direito Constitucional e Ciência Política. São Paulo: IBDC, n. 27, abr.-jun. 1999.

MENDES, Gilmar Ferreira. Direitos fundamentais e controle de constitucionalidade: estudos de direito constitucional. 4. ed., rev. ampl. São Paulo: Saraiva, 2012.

MENEZES, Aderson de. Teoria geral do Estado. 8. ed. rev. e atual. Rio de Janeiro: Forense, 2009, p. 237ss.

MIRANDA, Jorge. Manual de Direito Constitucional. 3.ed. Coimbra: Coimbra Editora, 2000, Tomo IV.

MÜLLER, Jörg Paul. Die Grundrechte der Verfassung und der Persönlichkeitsschutz des Privatrechts. Bern: Stämpfli, 1964.

MÜLLER-GRAFF, Peter-Christian. Die wettbewerbsverfaßte marktwirtschaft als gemeineuropäisches Verfassungsprinzip? Europarecht. Baden-Baden: Nomos, 1997.

MÜNCH, Ingo von. Die Drittwirkung von Grundrechten in Deutschland. In: SALVADOR CODERCH, Pablo. (Coord.). Zur Drittwirkung der Grundrechte. Frankfurt: Peter Lang, 1998.

NARANJO DE LA CRUZ, Rafael. Los límites de los derechos fundamentales em las relaciones entre particulares: la buena fe. Madrid: Centro de Estudios Políticos y Constitucionales, 2000.

NIPPERDEY, Hans Carl. Die Würde des Menschen. In: NEUMANN, Franz L; NIPPERDEY, Hans Carl; SCHEUNER, Ulrich (Hrsg.). Die Grundrechte. Handbuch der Theorie und Praxis der Grundrechte. Berlin: Duncler \& Humblot, 1954, Band II.

NIPPERDEY, Hans Carl. Grundrechte und Privatrecht. In: NIPPERDEY, Hans Carl. (Hrsg.). Festschrift für Erich Molitor zum 75. Geburtstag. München und Berlin: Beck Verlagsbuchhandlung, 1962.

OLIVEIRA JUNIOR, José Alcebíades. Cultura da Democracia para Direitos Humanos Multiculturais. In: OLIVEIRA JUNIOR, José Alcebíades (Org.). Cultura e Prática dos Direitos Fundamentais. Rio de Janeiro: Lúmen Juris, 2010.

PÉREZ LUÑO, Antonio Enrique. Derechos Humanos, Estado de Derecho y Constitucion. 5.ed. Madrid: Tecnos, 1995.

PIEROTH, Bodo. Die Grundrechte des Grundgesetzes in der Verfassungstradition. In: MERTEN, Detlef; PAPIER, Hans-Jürgen (Hrsg.) Handbuch der Grundrechte in Deutschland und Europa (HDG). Band. II. Heidelberg: Müller, 2006. 
PIETZCKER, Jost. Drittwirkung - Schutzpflicht - Eingriff. In: MAURER, Hartmut. Das Akzeptierte Grundgesetz. Festschrift für Günter Dürig zum 70. Geburtstag. München: Beck, 1990.

RRÖTHEL, Anne. Verfassungsprivatrecht aus Richterhand? Verfassungsbindung und Gesetzesbindung der Zivilgerichtsbarkeit. JuS. München und Frankfurt: Beck, 2001.

RUFFERT, Matthias. Vorrang der Verfassung und Eigenständigkeit des Privatrechts. Eine verfassungsrechtliche Untersuchung zur Privatrechtswirkung des Grundgesetzes. Tübingen: Mohr Siebeck, 2001.

SARLET, Ingo Wolfgang. A eficácia dos direitos fundamentais: uma teoria geral dos direitos fundamentais na perspectiva constitucional. 11. ed. rev. e atual. Porto Alegre: Livraria do advogado, 2012.

SARLET, Ingo Wolfgang. Dignidade da pessoa humana e direitos fundamentais na Constituição Federal de 1988. 9. ed. rev. e atualiz. Porto Alegre: Liv. do Advogado, 2012.

SARLET, Ingo Wolfgang. Direitos Fundamentais e Direito Privado: algumas considerações em torno da vinculação dos particulares aos direitos fundamentais. In: SARLET, Ingo Wolfgang (org.). A Constituição Concretizada: construindo pontes com o público e o privado. Porto Alegre: Livraria do Advogado, 2000.

SARMENTO, Daniel. Direitos Fundamentais e Relações Privadas. Rio de Janeiro: Lúmen Juris, 2004.

SCHWEIZER, Rainer J. Die erneuerte schweizerische Bundesverfassung vom 18. April 1999. Jahrbuch des Öffentlichen Rechts der Gegenwart (JöR). Neue Folge, Band 48. Tübingen: Mohr, 2000.

SILVA, Vasco Manuel Pascoal Dias Ferreira da. Vinculação das Entidades Privadas Pelos Direitos, Liberdades e Garantias. Revista de Direito Público. Instituto de Direito Público. São Paulo: Revista dos Tribunais, n. 82, abr.-jun., 1987.

SILVA, Virgílio Afonso da. A Constitucionalização do Direito. Os direitos fundamentais nas relações entre particulares. São Paulo: Malheiros, 2005.

SOMBRA, Thiago Luís Santos. A Eficácia dos Direitos Fundamentais nas Relações Jurídico-Privadas. A identificação do contrato como ponto de encontro dos direitos fundamentais. Porto Alegre: Fabris, 2004.

SOUZA JUNIOR, Cezar Saldanha. Direito Constitucional, Direito Ordinário, Direito Judiciário. Cadernos do Programa de Pós-Graduação em Direito da Universidade Federal do Rio Grande do Sul, março de 2005.

SPIEß, Gerhard. Inhaltskontrolle von Verträgen - das Ende privatautonomer Vertragsgestaltung? Deutsches Verwaltungsblatt (DVBI). Köln: Carl Heymanns, 1994.

STARCK, Christian. Die Grundrechte des Grundgesetzes. Juristische Schulung (JuS). München und Frankfurt: Beck, 1981.

STARCK, Christian. Grundrechtliche Schutzpflichten. In: STARCK, Christian. Praxis der Verfassungsauslegung. Baden-Baden: Nomos, 1994.

STEIN, Ekkehart; FRANK, Götz. Staatsrecht. 20., neu. Auf. Tübingen: Mohr, 2007.

STEINMETZ, Wilson Antônio. A Vinculação dos Particulares a Direitos Fundamentais. São Paulo: Malheiros, 2004.

STERN, Klaus. Das Staatsrecht der Bundesrepublik Deutschland: Allgemeine Lehren der Grundrechte. München: Beck, 1988, Band III/1.

TAVARES, André Ramos. Curso de Direito Constitucional. 8 ed. São Paulo: Saraiva, 2010.

TEPEDINO, Gustavo. A incorporação dos direitos fundamentais pelo ordenamento brasileiro: sua eficácia nas relações jurídicas privadas. Revista da Ajuris. Porto Alegre: Associação dos Juízes do Rio Grande do Sul, n. 100, dezembro 2005. 
TRIBE, Laurence. American Constitucional Law. 2 ed. Mineola: Foundation Press, 1988.

TUSHNET, Mark. The issue of state action/horizontal effect in comparative constitutional law. Oxford University Press and New York University School of Law 2003, I Com, Volume 1, Number 1, 2003.

UBILLOS, Juan María Bilbao. ¿En qué medida vinculan a los particulares los derechos fundamentales? In: SARLET, Ingo Wolfgang (Org.). Constituição, direitos fundamentais e direito privado. Porto Alegre: Livraria do Advogado, 2003.

UBILLOS, Juan María Bilbao. La eficácia de los derechos fundamentales frente a particulares. Madrid: Centro de Estúdios Políticos y Constitucionales, 1997.

UNRUH, Peter. Zur Dogmatik der grundrechtlichen Schutzpflichten. Berlin: Duncker \& Humblot, 1996.

VALE, André Rufino do. A eficácia dos direitos fundamentais nas relações privadas. Porto Alegre: Sergio Antonio Fabris, 2004.

VEGA GARCÍA, Pedro de. Dificuldades y Problemas Para la Construcción de un Constitucionalismo de la Igualdad (en caso de la eficacia horizontal de los derechos fundamentales). In: PÉREZ LUÑO, Antonio Henrique (coord). Derechos Humanos y Constitucionalismo ante el Tercer Milenio. Madrid: Marcial Pons, 1996.

VIEIRA DE ANDRADE, José Carlos. Os Direitos Fundamentais na Constituição Portuguesa de 1976. 2.ed. Coimbra: Almedina, 2001.

Recebido em: 04/04/2020

Aprovado em:10/11/2020 